\title{
Invisible dye tracing - an efficient technique for study of groundwater channels
}

\section{Невидимото трасиране с багрила-ефективна техника за изследване на пътищата на подземните води}

\author{
Yavor Shopov ${ }^{1,2,3}$, Ivan Antonov ${ }^{2}$, Valentin Lozanov ${ }^{2}$, Pavlin Dimitrov ${ }^{4}$, Svetoslav Marinov ${ }^{4}$, \\ Efrosina Hristova ${ }^{4}$

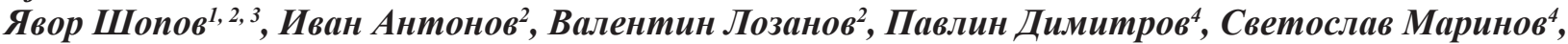 \\ Ефросина Христова ${ }^{4}$
}

\author{
${ }^{1}$ Faculty of Physics, Sofia University “St. K1. Ohridski”, Sofia; E-mail: yyshopov@yahoo.com \\ ${ }^{2}$ Medical University of Sofia, 2 Zdrave str., Sofia \\ ${ }^{3}$ Durban University of Technology, South Africa \\ ${ }^{4}$ Caving Club "Pod Raba"
}

\begin{abstract}
We studied excitation spectra of uranine fluorescence in eluates from charcoal traps saturated in cave waters and in reference uranine solutions and found that the most appropriate excitation wavelength is $295 \pm 5 \mathrm{~nm}$, because it excites fluorescence of uranine many times stronger than fluorescence of natural fluorescent compounds in groundwater. This allows us to lower the detection limit of uranine fluorescence with one order of magnitude, even below the level of natural fluorescence of karst waters at integral UV excitation.
\end{abstract}

Keywords: dye tracing, uranine, fluorescence, charcoal traps, groundwater.

В основата на настоящето изследване залегна използването на флуорохроми като трасиращи агенти и свидетели в зоните на очакван изход на подземните води (Smart, Karunaratne, 2002). За целта бе избран уранин с промишлена чистота. Регистрацията на уранина с помощта на капани с активен въглен повишава драстично ефективността на методиката и понижава границата на детектиране на багрилото с два порядъка. Затова ние използвахме методиката на семплиране на уранина с капани с активен въглен (Smart, 2002; Shopov et al., 2018). Извличането на уранина от активния въглен става със спиртен разтвор на калиева основа, а флуоресцентния спектър на уранина в алкална среда е с максимуми в $\lambda \approx 425 \mathrm{~nm}$ и $\lambda \approx 525 \mathrm{~nm}$. Основна пречка за откриването му в ниски концентрации в подземните води са хумусните и фулвокиселини, които са основната причина за флуоресценцията на природните води (Shopov, Stoykova, 2005). Допълнително предимство е неговата ниска биологична токсичност в детектируеми концентрации. Основен проблем за използването на багрила за трасирането на подземни води, които биха могли да се смесят с питейните води, е психологичния шок, който би предизвикала в местното население появата на светещо багрило в питей- ната вода. Именно такъв е случаят с трасирането на подземните води в пещерата Колкина дупка, с. Зимевица. Затова авторите се постараха да намалят количеството багрило, използвано за трасиране на подземните води. Планираше се детектирането на багрилото да не е визуално, a c капани с гранулиран активен въглен, заложен в проточната зона на изворите, последващо извличане на багрилото и измерване на интензитета и спектьра на неговата флуоресценция в лабораторни условия. Такава методика би позволила трасирането на подземните води с многократно по-малки количества багрило, които са под прага на визуално им детектиране в изворите. Обаче фоновата флуоресценция на природни органични примеси в подземните води, като хумусни и фулвокиселини, човешка и животинска урина, както и техногенни замърсявания на водите с нефтени продукти, антифриз и други, пречи на детектирането на трасиращите флуорохроми и води до повишаване на тяхната граница на откриване. Целта на настоящата работа е оптимизиране на лабораторните процедури за обработка на пробите и за регистрация на уранина, което да понижи границата на откриването му в реални условия (подземни води). Това ще позволи работа с по-малки количества багрило 
при трасиране на подземни води, водеща до пониските му концентрации в природните води и водоизточници, което ще позволи по-мащабно прилагане на трасиране на подземни води в хидрогеоложката практика.

Докато целта на предишната публикация (Shopov et al., 2018) беше трасиране на посоката на оттичане на водите от пещерата Колкина дупка с цел определяне на посоката на развитие на пещерата и евентуално откриване на неин втори вход, целта на това изследване е трасиране на оттичането на водите от пещерата Каците за свързването ѝ с пещерата Колкина дупка в една пещерна система с рекордни за страната размери.

$\mathrm{C}$ оглед известните теоретични и експериментални данни от Smart (2002) за зависимостта на ефективността на адсорбцията на активният въглен от дебита на водите в зоната на внасяне и очакваната концентрация на флуорохром в зоната на регистрация се прие стандартен 5 g капан (суха маса гранулиран активен въглен), заложен в проточната зона на реките.

Проведените теренни експерименти бяха насочени към проследяване и евентуално свързване на пътищата на подземните води, изтичащи от пещерата Каците, с вливащите се в реките в пещерата Колкина дупка, с. Зимевица, Свогенско. При успешно свързване на тези води могат да бъдат предприети проучвания на тези пещери с цел свързването им в една пещерна система, която би могла да бъде не само най-дълбоката (каквато сега е Колкина дупка), но и най-дългата в България. Така настоящето проучване придобива не само научно, методическо, но и практическо значение.
Преди да се пусне багрилото са поставени капани с 5 g активен въглен в четири независими реки в пещерата Колкина дупка, в които се очакваше поява на багрилото. В реката в пещерата Каците беше влят разтвор на 50 g уранин и $10 \mathrm{~g}$ натриев бикарбонат в 0,5 1 литра вода. Капаните бяха взети от изворите след 5 дена.

Разстояние между точката на пускане и на поява на индикатор е 1,38 километра, разлика в надморската височина 265 метра, време на достигане >5 денонощия, хидрогеоложки условия - ниски води.

Капаните бяха замразени поотделно до извличане на уранина и измерване на флуоресценцията му. Активният въглен е пренесен в стандартни $50 \mathrm{ml}$ пластмасови епруветки за центрофуга ("Falkon" type - Kartell ${ }^{\circledR}$ Germany) (т.н. фалкони) от $50 \mathrm{ml}$ и към всеки фалкон е добавен $20 \mathrm{ml}$ екстракционен раствор на 5\% KOH в 98\%ен $\mathrm{C}_{2} \mathrm{H}_{5} \mathrm{OH}$. Получените проби са ротирани на ротатор в продължение на $1 \mathrm{~h}$ при температура $24{ }^{\circ} \mathrm{C}$, след което по $14 \mathrm{ml}$ от течната фракция от всеки $50 \mathrm{ml}$ фалкон е пресипана в $15 \mathrm{ml}$-ови фалкони. Така получените течни фракции са центруфугирани в продължение на $15 \mathrm{~min}$ при 6000 rotations/min и от всяка проба е отделено по $1 \mathrm{ml}$ от супернатантата в епендорфки. Извлеците са центрофугирани при 13500 rotations/min за $15 \mathrm{~min}$ в 1,5 ml епруветки (“Eppendorf” type-Kartell ${ }^{\circledR}$ Germany). Получените проби имат слабо проявен твърд седимент в нищожни обеми на дъното.

При обльчване на 15-mm фалкони с лазер на $405 \mathrm{~nm}$ всички извлеци от пробите от 4-те изследвани реки в пещерата Колкина дупка (Un_0001 - Un_0004) демонстрираха видимо

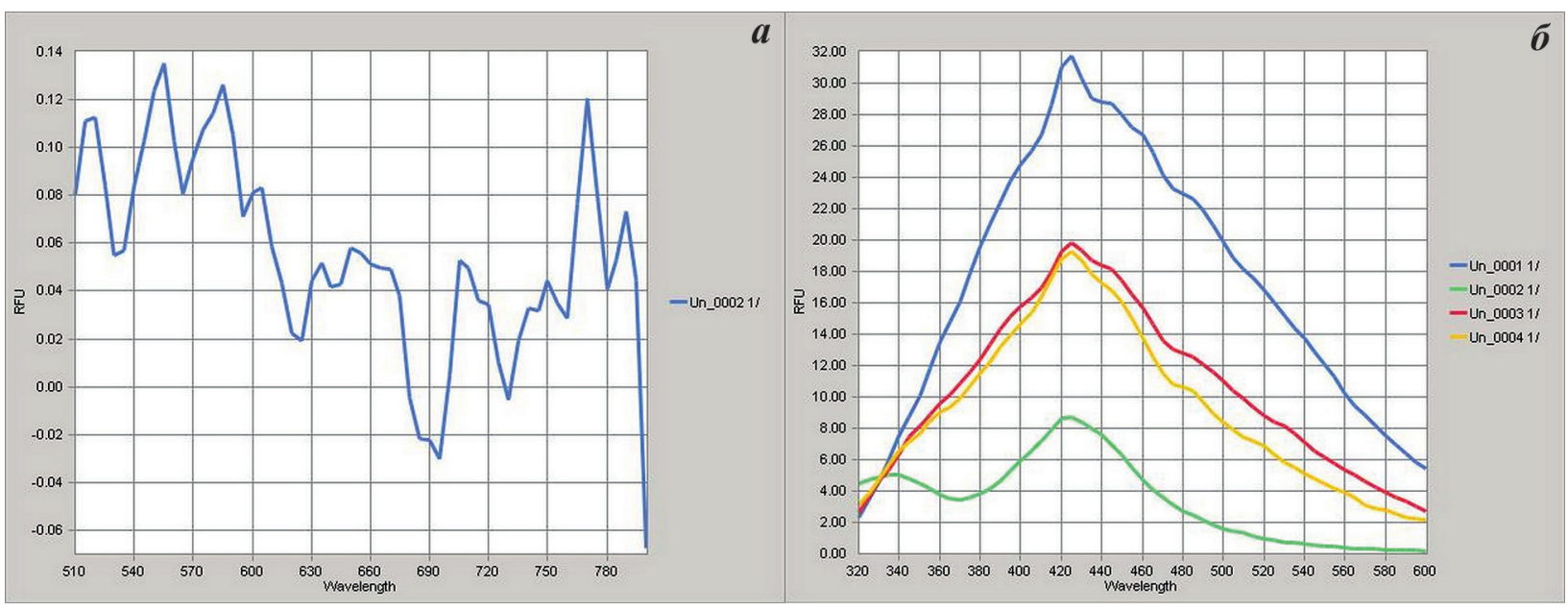

Фиг. 1. $a$, Un_0002, спектър на флуоресценция на уранин (при възбуждане със светлина с $\lambda \approx 480$ пm) в извлека от капана от T.2-Реката на Т-кръстовището; б, кривата, отбелязана с Un 0002-, е спектърьт на флуоресценция на уранин (при възбуждане със светлина с $\lambda \approx 295 \mathrm{~nm}$ ) в извлека от капана от Т.2-Реката на Т-кръстовището 
флуоресцентно светене. $200 \mu 1$ от всяка проба са поставени в 96-ямкова плака на спектрометър на Termo®Electron Varioscan ELISA и техните флуоресцентни спектри са измерени при възбуждане с дължина на вълната $\lambda$ ex $480 \pm 5 \mathrm{~nm}$. Спектьрьт на флуоресценция на уранин в алкална среда е с максимуми в $\lambda \approx 425 \mathrm{~nm}$ и $\lambda \approx 525 \mathrm{~nm}$. По тази причина измерихме интензитета на неговата флуоресценция в извлеците на тези дължини на вълната (фиг. 1).

Спектърьт на флуоресценция (фиг. 1а) на извлека от капана от Т.2-Реката на Т-кръстовището (Un_0002) при възбуждане с дължина на

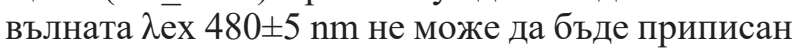
на уранин, защото не показва широката линия на флуоресценцията на уранина с максимум в $\lambda \approx 525 \mathrm{~nm}$. Това показва, че в реката, от която е взета пробата, водата не съдържа измерим процент води, идващи от Каците при възбуждане с дължина на вълната $\lambda \operatorname{ex~} 480 \pm 5 \mathrm{~nm}$, макар че извлека от този образец флуоресцира при облъчване с лазер на $405 \mathrm{~nm}$. Очевидно тази негова флуоресценция не се дължи на уранин, а на природни флуоресциращи примеси, т.е., това е фонова флуоресценция. Затова оптимизирахме регистрацията на малки количества флуоресцин, като използвахме възбуждане на флуоресценцията му в $\lambda \approx 295 \mathrm{~nm}$. При това вече успяхме да регистрираме флуоресценция на уранин (фиг. 1б) дори в извлека от капана от Т.2-Реката на Т-кръстовището (проба Un_0002). Така демонстрирахме, че оптимизирането на дължината на вълната на възбуждане на флуоресценцията на уранина позволява неговата регистрация дори под нивото на естествена флуоресценция на карстовите води при интегрално UV възбуждане.

\section{Заключение}

Установихме, че най-подходящата дължина на вълната на възбуждане на флуоресценцията на извлек на уранин от капани с активен въглен е $295 \pm 5 \mathrm{~nm}$, тъй като тя възбужда неговата флуоресценция в пъти по-силно от тази на естествените флуоресцентни съединения в подземните води. Това ни позволява да намалим границата на откриване на флуоресценция на уранин дори под нивото на естествена флуоресценция на карстовите води при интегрално UV възбуждане.

Благодарности: Това изследване е финансирано от ФНИ по проект ДН14/4.

\section{References \\ Литература}

Smart, C. C. 2002. Detection of fluorescent compounds in the environment using granular activated charcoal detectors. Environmental Geol., 42, 538-545.

Smart, C. C., K. C. Karunaratne. 2002. Characterisation of fluorescence background in dye tracing. - Envronmental Geol., 42, 492-498.

Shopov, Y. Y., D. Stoykova. 2005. Luminescence of speleothems in italian caves. - Acta Geol., 80, 105-109.

Shopov, Y., I. Antonov, V. Lozanov, S. Marinov, P. Dimitrov. 2018. Groundwater tracing in Kolkina Dupka cave, Zimevitsa village, by measuring of spectra of fluorescence of uranine in dilute from active coal traps. -Rev. Bulg. Geol. Soc., 79, 3,149-150 (in Bulgarian with English abstract). 